\title{
Protocolo de estudio cuasi-experimental para promover un estilo interpersonal de apoyo a la autonomía en docentes de educación física
}

\section{Protocol quasi-experimental study to promote interpersonal style autonomy support in physical education teachers}

\section{Protocolo de estudo quase-experimental para promover um estilo interpessoal de apoio à autonomia em professores de educação física}

\author{
Moreno-Murcia, J. A. ${ }^{1}$, Huéscar, E. ${ }^{1}$, Nuñez, J. L. ${ }^{2}$, León, J. ${ }^{2}$, Valero-Valenzuela, A. ${ }^{3}$, Conte, L. ${ }^{3}$ \\ ${ }^{1}$ Universidad Miguel Hernández de Elche; ${ }^{2}$ Universidad de las Palmas de Gran Canarias, ${ }^{3}$ Universidad \\ de Murcia.
}

\begin{abstract}
RESUMEN
Según la Teoría de la Autodeterminación (Deci y Ryan, 1985, 2002), el estilo interpersonal que utilice el educador puede tener un fuerte impacto en la motivación de los estudiantes. Los objetivos de este artículo fueron: (i) explicar la justificación y desarrollo de un programa de formación basado en esta teoría para promover el apoyo a la autonomía; (ii) describir el protocolo de intervención y los procedimientos de evaluación del programa de formación; y (iii) probar la integridad del protocolo de estudio para una futura intervención. De un total de 40 docentes de educación física, se asignarán 20 a un grupo de intervención o a un grupo control $(n=20)$. Durante un período de 8 semanas, los docentes del grupo de intervención participarán en un programa de formación en apoyo a la autonomía a través de varias fases. Se evaluarán indicadores que caracterizan el estilo interpersonal de apoyo a la autonomía de forma cualitativa y cuantitativa, referentes, tanto a la percepción del docente sobre su propia conducta, como a la percepción que tienen los estudiantes del estilo interpersonal del profesor. La recogida de los datos de la línea base cuantitativa se llevará a cabo un mes antes del inicio de la intervención y después se tomará otra medición un mes tras la finalización del período de intervención. Los datos cuantitativos se analizarán mediante análisis multinivel. Para explorar las percepciones del programa de formación, también se llevará a cabo un seguimiento a través de entrevistas semiestructuradas con docentes y miembros de la clase, entre la cuarta y la sexta semana después del final de la intervención. Este estudio cuenta con la aprobación del Comité de Ética de las instituciones participantes. Los hallazgos del estudio se difundirán a través de revistas de impacto científico y presentaciones en conferencias de carácter internacional.
\end{abstract}

Palabras clave: autodeterminación; ejercicio; docente; motivación; intervención; necesidades psicológicas básicas. 


\section{Moreno-Murcia, J. A., Huéscar, E., Nuñez, J. L., León, J., Valero-Valenzuela, A., Conte, L.}

\section{INTRODUCCIÓN}

En la investigación hasta el momento, el estilo motivacional del docente durante la interacción con sus estudiantes viene siendo destacado por su influencia sobre los ámbitos comportamental, cognitivo y emocional de los estudiantes (Hagger et al., 2009). A su vez, la educación física se presenta como una herramienta eficaz que puede ayudar a promover actitudes relacionadas con un estilo de vida activo fuera del entorno escolar (Beltrán, Devís, y Peiró, 2012; Biddle y Chatzisarantis, 1999; Digelidis, Papaioannou, Laparidis, y Christodoulidis, 2003). Sin embargo, un porcentaje importante de niños y adolescentes no cumple con las recomendaciones de práctica regular de actividad física propuestas por la OMS (OMS, 2016; Trost y Loprinzi, 2008). Así pues, pese a que el sedentarismo es perjudicial para la salud (Varo- Cenarruzabeitia y Martínez-González, 2006), fuera de la escuela, los niños suelen reemplazar la actividad física por otras actividades de carácter sedentario, como ver televisión y usar el ordenador (Poletti y Barrios, 2007). Dichas circunstancias justifican la necesidad de promocionar estilos de vida activos y saludables que formen parte de las prioridades educativas y sanitarias en diversos países (Consejo Superior de Deportes, 2008). Éste y otros objetivos similares para promover la salud (MorenoMurcia, Gea-Escámez, y Corbí, 2018), adquieren una importancia singular en la edad escolar, al tratarse de una etapa sensible para la formación de actitudes positivas hacia un estilo de vida saludable y, al mismo tiempo, por la marcada disminución de ejercicio que tiene lugar en la adolescencia (Butcher, Sallis, Mayer, y Woodruff, 2008; Gordon-Larsen, Nelson, y Popkin, 2004; Hernández et al., 2008). En este sentido, la investigación ha señalado que la actuación docente en clases de educación física está relacionada con la motivación para realizar ejercicio de forma regular (Cheon, Reeve, y Moon, 2012; Cheon y Reeve, 2015; De Meyer et al., 2016; Leptokaridou, Vlachopoulos, y Papaioannou, 2014; Yew y Wang, 2016). Así pues, diversos estudios, desde la Teoría de la Autodeterminación (SDT; Deci y Ryan, 1985, 2002), han estudiado los diferentes tipos de estilos interpersonales docentes existentes, concretando en un modelo dual que iría desde un estilo altamente controlador a otro altamente autónomo (Deci, Schwartz, Scheinman, y Ryan, 1981; Reeve y Tseng, 2011). Es decir, que los patrones comportamentales de los docentes estarían distribuidos desde unos que se caracterizan por apoyar la autonomía de sus estudiantes hasta otros que controlan todos los factores personales y ambientales durante su participación en las actividades de clase. En este sentido, numerosos trabajos coinciden en señalar la conveniencia en la adopción de estilos de apoyo a la autonomía frente al control por las consecuencias positivas demostradas para docentes y discentes tanto a nivel cognitivo, emocional y comportamental (Cheon y Reeve, 2015; Jang, Reeve, y Halusic, 2016). Sin embargo, pese a la necesidad de contribuir en esta dirección minimizando a su vez el alto porcentaje de patrones controladores exhibidos en el ámbito educativo en la actualidad, son escasos los trabajos que en esta dirección se han llevado a cabo para identificar programas eficaces de formación a los docentes en apoyo a la autonomía y/o motivación (Hancox, Quested, Thøgersen-Ntoumani, y Ntoumanis, 2015b). Por lo tanto, los objetivos de este estudio son explicar la justificación y desarrollo de un programa de formación basado en la SDT para promover el apoyo a la autonomía en docentes y generar resultados adaptativos en sus estudiantes, describir el protocolo de intervención y los procedimientos de evaluación del programa de formación y probar la integridad del protocolo de estudio para que pueda ser replicado en futuros estudios.

\section{Estilo interpersonal de apoyo a la autonomía en educación física}

A partir de la SDT (Deci y Ryan, 1980, 1985; Vallerand, 1997) se viene avanzando en la comprensión sobre la incidencia de los factores sociales en la motivación $\mathrm{y}$, por tanto, en la satisfacción de las necesidades psicológicas básicas fundamentales de competencia, autonomía, y relación con los demás. Según estos autores, los factores sociales que satisfacen estas necesidades promoverán formas de motivación autodeterminadas $\mathrm{y}$, a su vez, conllevarán consecuencias cognitivas, afectivas y conductuales adaptativas. Puesto que la motivación docente se asocia con la motivación de los estudiantes (Pelletier, Seguin-Lévesque, y Legault, 2002) y en un marco donde el desarrollo de las competencias son el centro de los procesos de enseñanza-aprendizaje, los docentes podrían estimular el pensamiento creativo, favorecer en los estudiantes el desarrollo de 


\section{Protocolo de apoyo a la autonomía en educación física}

conocimientos, habilidades, actitudes y valores, de modo que les permitan integrar sus aprendizajes y transferirlos en cualquier contexto. Esta situación requiere de una mayor exigencia por parte del profesorado, $y$, en ocasiones, no se les proporciona los recursos necesarios para hacer frente a las nuevas demandas del sistema educativo, factor que podría generar cierto malestar entre este colectivo provocando una disminución de su motivación.

Según Deci y Ryan (1991), el contexto social óptimo para favorecer un comportamiento autodeterminado es aquel que optimiza el desarrollo de la autonomía, establece una estructura adecuada y supone la implicación de los otros significativos. Apoyados en esta teoría, el apoyo a la autonomía se presenta como un factor importante que puede influir en la capacidad de las personas para prosperar, mejorar su crecimiento personal y satisfacción. De esta forma, la SDT (Ryan y Deci, 2000, 2002) propone que el estilo de enseñanza del docente que apoya a la autonomía de sus estudiantes se caracteriza por involucrarse en la actividad, estando relacionada con sus intereses, valores y con la satisfacción con la vida. Por ejemplo, los docentes que apoyan la autonomía tienen en cuenta las perspectivas, pensamientos y sentimientos de sus estudiantes, apoyando su capacidad de desarrollo para autorregularse de forma autónoma, motivándoles a través del fomento de sus recursos motivacionales internos, ofreciéndoles razones explicativas, utilizando un lenguaje informativo y mostrando paciencia. Sin embargo, los docentes con un estilo controlador promueven malestar entre sus estudiantes (De Meyer et al., 2014; Reeve y Tseng, 2011). Así pues, quieren que sus estudiantes tengan sólo la perspectiva que ellos imponen, entrometiéndose en los pensamientos, sentimientos y acciones del estudiante, induciéndolos a pensar, sentir y actuar a partir de su criterio. Además, motivan a los estudiantes exclusivamente a través de incentivos extrínsecos, utilizan un lenguaje directivo y muestran impaciencia para producir la respuesta correcta o el comportamiento requerido (Reeve, 2009).

Algunas investigaciones han abordado la formación de docentes para desarrollar estilos interpersonales de apoyo a la autonomía con resultados muy positivos en educación física (Cheon y Reeve, 2013, 2015; Cheon et al., 2012; Cheon, Reeve, Lee, y Lee, 2018; Cheon, Reeve, y Ntoumanis, 2018; Escriva-Boulley, Tessier,
Ntoumanis, y Sarrazin, 2018; Lonsdale et al., 2016; Perlman, 2015; Tessier, Sarrazin, y Ntoumanis, 2008, 2010). Estos programas se han aplicado con éxito en docentes en prácticas, en recién egresados y en docentes con amplia experiencia, de ambos géneros y diferentes nacionalidades, y que ejercían en todas las etapas del sistema educativo (Perlman, 2015; Reeve y Jang, 2006; Reeve et al., 2014; Tessier et al., 2008). Pero, a pesar de esto, son escasos los estudios que muestran los protocolos de los programas en esta dirección. Por lo tanto, consideramos que puede ayudar al colectivo académico y profesional mostrar el desarrollo teórico y empírico de la puesta en marcha de programas de formación que fomenten el estilo interpersonal de apoyo a la autonomía a través de una secuenciación programada de módulos de formación.

\section{Enseñar a los docentes de educación física a dar apoyo a la autonomía}

Anteriores estudios han descrito que es posible entrenar a las personas para utilizar un estilo interpersonal de apoyo a la autonomía (Cheon et al., 2018; Ng et al., 2012; Reeve y Cheon, 2014, 2016). Los estudios se han centrado principalmente en los resultados de la formación en las conductas esperadas $\mathrm{y}$ en mejorar la motivación de los estudiantes comprobando su efectividad (Su y Reeve, 2011), y, en menor medida, en especificar cómo se capacitó a los docentes y si dicha formación fue factible y posteriormente utilizada con altos niveles de fidelidad (Ntoumanis, Thøgersen-Ntoumani, Quested, y Hancox, 2016).

Para conseguir que los docentes puedan dar un adecuado apoyo a la autonomía es importante en el proceso de formación de éstos, utilizar técnicas de cambio conductual (Hagger, Keatley, Chan, y Derwin, 2014). La eficacia de estas intervenciones no solo se basa en que los docentes comprendan y avalen la importancia de dar apoyo a la autonomía, sino también tener la voluntad de cambiar la dirección de su conducta y aplicar las estrategias de motivación de manera efectiva. En este sentido, Ntoumanis et al. (2016) desarrollan y evalúan un protocolo de entrenamiento a los formadores para motivar de manera más eficaz. Se centra en informar sobre cualquier cambio de comportamiento derivado de las técnicas empleadas, mostrando si los materiales de intervención están adaptados apropiadamente, pero en el contexto del ejercicio físico saludable (ciclo 


\section{Moreno-Murcia, J. A., Huéscar, E., Nuñez, J. L., León, J., Valero-Valenzuela, A., Conte, L.}

indoor). Hagger et al. (2014) han realizado una adaptación de las técnicas de cambio conductual CALO-RE (Michie et al., 2011) al ejercicio físico. La aplicación de la taxonomía CALO-RE ha sido utilizada en el estudio de Ntoumanis et al. (2016). Así pues, para apoyar a los educadores en su cambio de conducta, esta propuesta de programa de formación en el ámbito educativo, adaptará y utilizará técnicas de cambio conductual descritas en estos estudios.

\section{La intervención propuesta}

El estudio propuesto se basará en evidencias previas que han sido utilizadas para formar a docentes con el objetivo de adquirir un estilo interpersonal de apoyo a la autonomía. Además, los objetivos previos serán ampliados de varias maneras: (1) identificación y proporción de descripciones detalladas de estrategias de apoyo a la autonomía que puedan ser utilizadas por los docentes para apoyar los recursos intrínsecos del estudiante, (2) capacitación a los docentes no sólo a utilizar estrategias de apoyo a la autonomía, sino también sobre cómo minimizar el uso de estrategias controladoras, y cómo cambiar una conducta controladora por otra de apoyo a la autonomía, (3) complementación de los talleres de formación presenciales con otros online, junto con los foros y materiales didácticos, así como con diversos ejercicios online, (4) grabación en vídeo las clases de los docentes antes y después de la capacitación para evaluar la eficacia de la intervención para medir objetivamente los cambios producidos en el estilo interpersonal, (5) evaluación del impacto de la intervención sobre la motivación de los estudiantes y los educadores, y (6) análisis de los datos de los cuestionarios, entrevistas a los docentes y ejercicios para establecer el efecto de la formación, así como sus efectos en la motivación de los estudiantes y otras variables cognitivas, comportamentales y emocionales relacionadas.

Se determinará la eficacia del programa de intervención mediante la puesta a prueba de los procedimientos de evaluación, con el interés de que el protocolo de estudio pueda ser replicado en un futuro, constituyendo una herramienta válida y eficaz de formación docente. Dicho programa estará basado en el estilo interpersonal de apoyo a la autonomía fundamentado en la SDT personalizada para docentes de educación física (Bartholomew, Ntoumanis, y Thøgersen-Ntoumanis, 2009; Reeve y Jang, 2006;
Van de Berghe et al., 2013). Las clases de educación física se caracterizan por ofrecer una experiencia de tareas grupales estructuradas, por lo que los hallazgos de este estudio serán potencialmente aplicables a otros tipos de clases estructuradas. Se buscará una consulta con docentes experimentados para garantizar que los materiales de intervención se adapten adecuadamente para el entorno y la población en estudio. Se identificarán qué estrategias de apoyo a la autonomía son más aplicables al contexto de la educación física y cómo estas estrategias pueden llevarse a la práctica dentro del mismo. El programa de formación se centrará en fomentar en los docentes el uso de las estrategias de apoyo a la autonomía y minimizar o sustituir el de estrategias controladoras.

Se examinará la viabilidad de la aplicación de la intervención, comprobando sus efectos sobre docentes y discentes. Concretamente, los principales objetivos de este trabajo son: (i) explicar la justificación y desarrollo de un programa de formación basado en la SDT para promover el apoyo a la autonomía; (ii) describir el protocolo de intervención y los procedimientos de evaluación del programa de formación, y (iii) probar la integridad del protocolo de estudio para una futura intervención.

\section{MATERIAL Y MÉTODOS}

\section{Diseño del estudio y entorno}

Se llevará a cabo un estudio para (i) determinar la aceptabilidad de una intervención de formación en apoyo a la autonomía basada en la SDT para docentes de educación física y (ii) comprobar si los procedimientos de ensayo, métodos, y el protocolo son viables para la intervención que se describe posteriormente. Los participantes serán alumnos de primaria o secundaria y sus docentes de educación física. El estudio será un diseño cuasi-experimental con grupo cuasi-control. Veinte docentes de educación física serán asignados al grupo de intervención y 20 al grupo control. Los docentes serán la unidad de asignación de grupo. Los estudiantes que participen en el estudio no conocerán los objetivos del tratamiento de intervención, pues se les pedirá a los docentes del grupo de intervención no mencionar nada del proceso de formación recibido a sus estudiantes. Las medidas de resultado serán recogidas al inicio del estudio y cuatro semanas después. El protocolo (Figura 1) de 


\section{Protocolo de apoyo a la autonomía en educación física}

este diseño se ha descrito de conformidad con las guías SPIRIT (2013).

\section{El reclutamiento de participantes y su elegibilidad}

Los docentes serán reclutados en parte, a través de los datos de contacto proporcionados por las Consejerías de Educación. Para poder participar en el programa, los docentes tendrán que cumplir los siguientes requerimientos (i) ser un docente interino $o$ funcionario de educación física de Educación Primaria o Secundaria, (ii) tener asignadas clases con el grupo durante todo el curso escolar elegido para la intervención, (iii) y contar con el visto bueno de: la

Consejería de Educación y por parte del centro educativo, del Consejo Escolar junto al de los padres o tutores mediante consentimiento informado, debido a la condición de que los estudiantes que participarán en ambos grupos (intervención y control) son menores de edad. Así pues, se les solicitará que asuman el modelo de información (Anexo I), completen un formulario de consentimiento (Anexo II), y un paquete cuestionarios para los docentes (Anexo IV). Además, los estudiantes de cada clase tendrán que cumplir los siguientes criterios de elegibilidad: (i) contar con la autorización del tutor responsable (Anexo III) y (ii) completar y devolver el paquete de cuestionarios que se les pedirá en los tiempos oportunos (Anexo V).

Los estudiantes participantes serán el alumnado que los docentes implicados en la formación tendrán en ese momento en sus clases. Se adoptará como criterio de exclusión asistir a menos del $80 \%$ de las clases.

\section{La intervención.}

Se ha diseñado con el objetivo principal de capacitar a los docentes de educación física para adoptar un estilo interpersonal de apoyo a la autonomía fundamentado en la SDT. Esta formación se centrará en que el profesorado domine los recursos en el aula relacionados con el apoyo a: la autonomía, la estructura y la relación. Además, al final del proceso de formación el profesorado deberá ser capaz de diseñar tareas manteniendo un estilo de comunicación de apoyo a la autonomía y no controlador o neutro, además de aprender a cambiar un estilo controlador por uno que apoye la autonomía. En la Tabla 1 quedan recogidas las características principales de cada uno de estos estilos.
En primer lugar, en cuanto al apoyo a la autonomía, consistirá en crear ambientes de aprendizaje que promuevan el interés de los estudiantes, atienda a sus preferencias y busque generar metas personales, siendo paciente con sus ritmos de aprendizaje. También fomentará que sus estudiantes movilicen sus recursos motivacionales internos y el pensamiento independiente, desencadenando la ejecución de las tareas por iniciativa propia (Tabla 2).

\section{AQUÍ TABLA 1 Y TABLA 2}

En segundo lugar, respecto al apoyo a la estructura en la tarea (Tabla 3), consiste en guiar el proceso de aprendizaje proporcionando estrategias y ayuda para que los estudiantes se sientan competentes respecto a la realización de las actividades (Hancox et al., 2015b). Se incluyen dos momentos importantes para suministrar los apoyos a los estudiantes: antes y durante la tarea. Respecto al primero, los comportamientos que se dan antes de la tarea tendrán como finalidad proporcionar una guía sobre qué se va a desarrollar y cómo se va a plantear la instrucción para ayudarles en su aprendizaje; tendrá que ofrecer indicaciones y explicaciones previas al desarrollo práctico de las actividades, exponer los criterios e indicadores generales encaminados a promover la autorregulación del proceso de aprendizaje. En cuanto a los segundos, los apoyos proporcionados durante la tarea, tendrán como objetivo integrar las instrucciones y pautas que el docente ofrece de forma clara y concisa durante la ejecución de las tareas, con la finalidad que los estudiantes sepan qué hacer y puedan modular su aprendizaje; contempla las variantes y alternativas para atender a la diversidad de ritmos y estilos de aprendizaje durante la acción; comprende el feed-back positivo como los refuerzos positivos, elogios y/o ánimos y explicativos como el razonamiento y tratamiento del error, ayudas y sugerencias, que se va ofreciendo durante el desarrollo de las tareas con la finalidad de colaborar en la construcción de sus aprendizajes.

\section{AQUÍ TABLA 3}

$\mathrm{Y}$ en tercer lugar, en cuanto al apoyo a la relación, consiste en que los docentes manifiesten un tratamiento hacia los estudiantes de calidez y cuidado. Se caracteriza por ser un docente empático con los problemas y necesidades de los estudiantes, escuchándolos y atendiéndolos con educación y 


\section{Moreno-Murcia, J. A., Huéscar, E., Nuñez, J. L., León, J., Valero-Valenzuela, A., Conte, L.}

respeto. Tendrá que representar un modelo positivo que se caracterice por mostrar entusiasmo e ilusión por su trabajo, siendo capaz de transmitirlo en cada clase (Tabla 4).

\section{AQUÍ TABLA 4}

Por otro lado, la intervención también estará basada en las técnicas de cambio comportamental de la taxonomía CALO-RE (Hagger et al., 2014; Hancox, Ntoumanis, Thøgersen-Ntoumani, y Quested, 2015a; Michie et al., 2011). En la Tabla 5 se muestran las principales estrategias que se utilizarán durante el proceso de cambio conductual con el objetivo de conseguir un estilo de interacción de apoyo a la autonomía.

\section{AQUÍ TABLA 5}

Respecto al ámbito de aplicación, la intervención será desarrollada y personalizada para el contexto de educación física. Cuatro expertos en la materia se encargarán de supervisar las conductas ejecutadas por cada docente. Las observaciones recogidas por los expertos se podrán utilizar para (i) identificar los estilos actuales y estrategias de apoyo a la autonomía adoptadas por los docentes, (ii) el grado en que las características del estilo interpersonal del docente de educación física se alinean o entran en conflicto con el apoyo a la autonomía, y (iii) las barreras potenciales para los docentes que frenan la creación de entornos de apoyo a la autonomía en las clases de educación física (Figura 1).

\section{AQUÍ FIGURA 1}

\section{Formación presencial.}

La formación incluirá cuatro talleres con una duración de tres horas presenciales cada uno. Los talleres tendrán el formato de un seminario interactivo, donde se llevarán a cabo discusiones y actividades en grupo, intercambio de ideas, diseño de tareas e incluirán el abordaje conceptual y práctico de las estrategias de apoyo a la autonomía. En el primer taller, se buscará que el docente diagnostique el estilo didáctico que emplea de forma habitual durante sus clases. Para ello, se aportará un instrumento de autoevaluación simple y objetivo. Además, en esta fase se focalizará en la naturaleza y características del estilo docente controlador y se mostrarán los efectos negativos del mismo. En el segundo y tercer taller, se propone conocer, desarrollar y perfeccionar las habilidades interpersonales y comportamientos de enseñanza propios del apoyo a la autonomía. Se crearán oportunidades de carácter práctico para que los docentes puedan compartir sus experiencias al poner en práctica las estrategias, y poder explorar y trabajar juntos para hacer frente a cualquier desafío.

Se analizarán ejemplos de situaciones en las que pueda observar la utilización de estrategias de apoyo a la autonomía, debatir por qué la estrategia se asocia con dicho estilo, y reflexionar sobre qué implicaciones tendría para los estudiantes, tanto a nivel cognitivo, como conductual y afectivo. También se analizarán ejemplos reales aportados por los docentes en los que se aplica un estilo controlador y se proporcionarán sugerencias para cambiarlas por otro basado en el estilo de apoyo a la autonomía. En el cuarto taller, que se desarrollará después de la formación online, tratará de avanzar en la evaluación del estilo motivador docente. Para ello, cada docente tendrá que traer grabado en vídeo la parte central de una clase (en la que al menos se explique y desarrolle una tarea completa) con una duración aproximada de 20 minutos. Estos vídeos se analizarán desde la evaluación $360^{\circ}$, teniendo en cuenta tres perspectivas: el mismo docente, la percepción de otro igual (docente) y un investigador experto. A través de la reflexión en pequeños grupos, se pretende llegar al dominio e identificación de las conductas con apoyo a la autonomía. Desde que da comienzo, como parte de la estrategia de implementación, se animará a los docentes a mantener una reflexión a través de un diario (Anexo VIII), donde puedan registrar sus pensamientos y sentimientos en relación con las ideas exploradas en los talleres y en sus experiencias prácticas al llevarlas a cabo. El equipo de investigación estará disponible para proporcionar una respuesta inmediata y responder preguntas durante estas sesiones.

Toda la información que se trate en los talleres (presentaciones, materiales educativos, descripciones narrativas de cada una de las estrategias de apoyo a la autonomía recomendadas, etc.) será facilitada a través de un blog especializado en la temática de apoyo a la autonomía en educación (apoyoalaautonomia.edu.umh.es). Además de animar a los docentes a acceder al blog, se les ofrecerá la 


\section{Protocolo de apoyo a la autonomía en educación física}

posibilidad de participar en un foro de discusión privado de Facebook que se utilizará para proporcionar recursos adicionales (vídeos), informaciones complementarias (ideas adicionales sobre cómo se podrían implementar las estrategias), apoyo (las respuestas a las preguntas y dificultades a que se enfrentan los docentes), y debate (entre docentes con respecto a sus experiencias, y/o con el equipo de investigación) a lo largo de todo el proceso de formación. También se ofrecerá un teléfono y correo electrónico de apoyo adicional del responsable del equipo de investigación. Se alentará a los docentes a poner en práctica las estrategias facilitadas a lo largo del período de intervención para planificar y optimizar su propio estilo docente.

\section{Formación online.}

Entre el taller presencial tercero y el cuarto se facilitará a través de un entorno virtual un espacio donde se incluirán vídeos de docentes que demuestran tanto estrategias de apoyo a la autonomía como controladoras. Además, se ofrecerán documentos en formato pdf que complementará la formación, por ejemplo, tras la visión de un vídeo que muestra cómo motivar a los estudiantes tendrán que contestar un pequeño test que nos permitirá comprobar el conocimiento sobre el mismo. Se proporcionará una formación online organizada por estrategias para que todos los docentes experimenten la formación en los mismos tiempos. Esta sintonía permitirá, paralelamente a todos, poder tener discusiones de grupo sobre las estrategias particulares a través de la página del grupo de Facebook. Cada semana, se compartirán a través de Facebook tres o cuatro estrategias de apoyo a la autonomía, junto con imágenes relevantes, vídeos o preguntas de discusión. En todo momento, se llevará a cabo una supervisión por parte del experto para apoyar a los docentes a través del grupo de Whatsapp, Facebook o correo electrónico.

\section{Recopilación de datos}

Se emplearán tres técnicas de recogida de datos: cuestionarios, observación y entrevistas individuales semiestructuradas. Los cuestionarios se utilizarán para analizar las percepciones de los docentes y estudiantes, la observación se utilizará únicamente con los docentes, mientras que las entrevistas semiestructuradas se utilizarán para obtener información de los docentes y los estudiantes.

Los cuestionarios y la observación se recogerán dos veces, antes y después de la formación. La evaluación previa se realizará aproximadamente un mes antes de empezar la intervención (tiempo 1; T1), mientras que la evaluación posterior se realizará un mes después (tiempo 2; T2). Las entrevistas semiestructuradas se llevarán a cabo entre la semana cuarta y sexta después de finalizar la intervención (Figura 1).

\section{Adherencia}

Para comprobar la adherencia a la intervención, los investigadores llevarán un registro de los docentes que asisten a cada taller. La formación online, se comprobará a través de un test online. Si alguno de los participantes abandona el estudio, siempre que sea posible, telefónicamente se le consultará las razones.

\section{Cuestionarios}

\section{Estudiantes.}

Los resultados del cambio se comprobarán desde el inicio midiendo las percepciones que los estudiantes tienen del estilo interpersonal utilizado por su docente a través del Interpersonal Behavior Scale (Pelletier, Beaudry, Sharp, y Otis, 2008) validada al contexto español por Moreno-Murcia y Corbí (en prensa). Además, pasado un mes se comprobará también la motivación que tienen los estudiantes para asistir a las clases (PLOC, Goudas, Biddle y Fox, 1994; Moreno, González-Cutre, y Chillón, 2009) y la satisfacción de las necesidades psicológicas básicas (BPNS, Vlachopoulos, y Michailidou, 2006; Moreno, González-Cutre, Chillón, y Parra, 2008). La intención de seguir practicando ejercicio fuera del entorno académico se medirá a través del instrumento MIFA (Hein, Müür, y Koka, 2004; Moreno, Moreno, y Cervelló, 2007).

\section{Docentes.}

Las percepciones de los docentes sobre el apoyo, la estructura y la relación, así como el estilo controlador se medirán utilizando las mismas escalas que las empleadas para estudiantes, pero con pequeñas modificaciones para adaptar la redacción a los estudiantes. También se evaluará la satisfacción de las 


\section{Moreno-Murcia, J. A., Huéscar, E., Nuñez, J. L., León, J., Valero-Valenzuela, A., Conte, L.}

necesidades psicológicas básicas (Escala de Satisfacción de las Necesidades Psicológicas Básicas, Gillet, Rosnet, y Vallerand, 2008; León, Domínguez, Núñez, Pérez, y Martín-Albo, 2011) y la motivación para dar clases (Escala de Motivación Educativa, Vallerand, Blais, Briere y Pelletier, 1989; Núñez, Martín-Albo y Navarro, 2005).

\section{Observación.}

Las clases de los docentes serán grabadas en vídeo en dos ocasiones, durante los períodos T1 y T2. Un investigador entrenado colocará la cámara de vídeo en un lugar discreto en la clase y con un ángulo lo suficientemente amplio para grabar todas las acciones del docente en clase. Para la identificación de las estrategias de apoyo a la autonomía empleadas por el docente durante la clase se utilizará la herramienta de codificación creada a tal fin (Barrachina, 2017). Esta escala contempla cuatro dimensiones; autonomía, estructura antes de la tarea, estructura durante la tarea y relación. Se observará a ambos grupos (control e intervención) y se analizará el impacto del estilo interpersonal docente orientado al control, al estilo neutro y al apoyo a la autonomía. Existen estudios que han realizado mediciones similares (Aelterman et al., 2014; Haerens et al., 2013; Perlman, 2015), de acuerdo con éstos, del total de las interacciones registradas, un mínimo del $80 \%$, debería desarrollarse por medio el estilo de apoyo a la autonomía en el grupo de intervención. Después del entrenamiento, dos codificadores ciegos a la condición (intervención o control) codificarán la intervención.

\section{Entrevistas.}

Al final del período de intervención, se llevarán a cabo entrevistas individuales semiestructuradas con aproximadamente 10 docentes del grupo de formación elegidos al azar (Anexo VI). Las entrevistas se centrarán en la viabilidad de la formación, la adherencia y las barreras a la participación en la intervención y/o aplicación de las estrategias de apoyo a la autonomía. Además, se pedirá a los docentes que compartan sus diarios de reflexión y planes de acción con el equipo de investigación. Para explorar las razones de la deserción, también se llevarán a cabo entrevistas individuales con los docentes que hayan abandonado. Para explorar los efectos de la intervención sobre los estudiantes, se llevarán a cabo entrevistas individuales semiestructuradas con una submuestra de 15 estudiantes elegidos al azar (Anexo VII).

\section{Análisis de los datos}

Se realizarán análisis estadísticos descriptivos para informar sobre la adherencia y abandono de los participantes. También se aportará información sobre la media y desviación típica antes y después de la intervención respecto a las variables de medida, diferenciando entre los participantes del grupo experimental y del grupo control. Debido a que el alumnado está agrupado en aulas es necesario conocer el efecto de la intervención a nivel grupal y a nivel individual. Para analizar este efecto se llevará a cabo un análisis multinivel en el que se probará si los participantes del grupo experimental y los del grupo control siguen trayectorias diferentes, por ejemplo, si la percepción del apoyo a la autonomía sigue una trayectoria descendente en el grupo control y una trayectoria ascendente en el grupo experimental. Dada la naturaleza del marco teórico de la intervención, el análisis se enfocará no solo en identificar si la intervención tiene algún impacto en los cambios en las variables, sino también en por qué es efectivo al probar los principios subyacentes de la teoría (Moore et al., 2014), para ello se analizará el efecto indirecto de las variables mediadoras (autonomía, competencia y relaciones). Para analizar la información obtenida mediante las entrevistas semiestructuradas a los docentes y los estudiantes se utilizar el análisis temático inductivo (Braun y Clarke, 2006).

\section{Las cuestiones éticas y de difusión}

El estudio deberá contar con la aprobación del Comité de Ética de las instituciones participantes. Se requerirá el consentimiento informado por escrito de todos los participantes antes de participar en el estudio. Todos los participantes potenciales (los docentes y sus estudiantes) se les darán una carta de información que describirá las implicaciones de su participación, e indicará que la participación es voluntaria y que son libres de abandonar en cualquier momento. Aunque no existen riesgos físicos, psicológicos, económicos, sociales o conocidos asociados a la participación, se ofrecerá a los participantes el apoyo necesario si fuera preciso. Todos los datos recogidos se mantendrán archivados de forma confidencial y se almacenarán de forma segura en línea con las directrices establecidas por la Universidad respecto a la protección de datos. 


\section{Protocolo de apoyo a la autonomía en educación física}

Todos los documentos y datos registrados en papel serán almacenados en un armario cerrado con llave. Todos los datos electrónicos se almacenarán de forma segura en un ordenador portátil protegido por contraseña. Los documentos que contengan nombres o información de identificación personal se almacenarán por separado de los datos del estudio y se identificarán únicamente por un código numérico. Sólo el equipo de investigación tendrá acceso a los datos del estudio. Los hallazgos del estudio se podrán difundir a través de revistas y presentaciones en conferencias.

\section{CONCLUSIONES}

En este artículo se describe la justificación y el diseño de un estudio para desarrollar, implementar y poner a prueba un programa de intervención basado en los principios de la Teoría de la Autodeterminación para mejorar el apoyo a la autonomía en docentes de educación física. No sólo es necesario probar si una intervención produce los efectos deseados, sino que también es pertinente entender por qué una intervención es o no es factible, eficaz o sostenible. Una de las ventajas clave del diseño de la intervención propuesta es que está fundamentada en una teoría existente (SDT), esto ayuda a obtener evidencia de los mecanismos por los que la intervención puede o no puede tener éxito.

Por otra parte, en el estudio se emplearán una serie de técnicas de cambio de conducta a través de diversos medios de comunicación (presencial y el uso de las redes sociales en línea, Facebook y Whatsapp) para apoyar y motivar a los docentes. Además, se emplearán evaluaciones cuantitativas objetivas $\mathrm{y}$ cualitativas para evitar el riesgo de la varianza del método común. Si la intervención tiene éxito, la motivación y adherencia del estudiante al ejercicio físico se podría mejorar. Además, los hallazgos pueden proporcionar evidencias para la optimización del desarrollo de programas de formación basados en la SDT.

\section{Agradecimientos}

Este documento ha sido financiado en parte por el proyecto de investigación DEP2017-83441-R titulado "Más allá del control: Consecuencias del fomento del apoyo a la autonomía en docentes y estudiantes en clases de educación física", perteneciente a la convocatoria 2017 de Proyectos I+D+I, del Programa
Estatal de Investigación, Desarrollo e Innovación orientada a los Retos de la Sociedad del Ministerio de Economía, Industria y Competitividad (España).

\section{REFERENCIAS}

1. Aelterman, N., Vansteenkiste, M., Van den Berghe, L., De Meyer, J., y Haerens, L. (2014). Fostering a need-supportive teaching style: Intervention effects on physical education teachers' beliefs and teaching behaviors. Journal of Sport \& Exercise Psychology, 36(6), 595-609. doi: 10.1123/jsep.2013-0229.

2. Barrachina, J. (2017). Efecto del apoyo a la autonomía en el enfoque por competencias en educación física. Tesis doctoral. Universidad Miguel Hernández de Elche.

3. Bartholomew, K. J., Ntoumanis, N., y ThøgersenNtoumani, C. (2009). A review of controlling motivational strategies from a self-determination theory perspective: Implications for sports coaches. International Review of Sport and Exercise Psychology, 2, 215-233. doi:10.1080/17509840903235330

4. Beltrán, V. J., Devís, J., y Peiró, C. (2012). Actividad física y sedentarismo en adolescentes de la Comunidad Valenciana. Revista Internacional de Medicina y Ciencias de la Actividad Física y el Deporte, 12(45), 122-137.

5. Biddle, S. J., y Chatzisarantis, N. (1999). Motivation for a physically active lifestyle through physical education. En Vanden, Y., Bakker, F., Biddle, S., Durand, M. y Seiler, R. (Eds.), Psychology for physical educators (pp. 5-26). Champaign, IL: Human Kinetics.

6. Braun, V., y Clarke, V. (2006). Using thematic analysis in psychology. Qualitative Research in Psychology, 3, 77-101. doi:10.1191/1478088706qp063oa

7. Butcher, K., Sallis, J. F., Mayer, J. A., y Woodruff, S. (2008). Correlates of physical activity guidelines compliance for adolescents in 100 U.S. cities. Journal of Adolescent Health, 42, 360-368. doi.org/10.1016/j.jadohealth.2007.09.025

8. Chatzisarantis, N. L. D., y Hagger, M. S. (2009) Effects of an intervention based on selfdetermination theory on self-reported leisure-time physical activity participation. Psychology and Health, 24(1), 29-48. doi: $10.1080 / 08870440701809533$ 


\section{Moreno-Murcia, J. A., Huéscar, E., Nuñez, J. L., León, J., Valero-Valenzuela, A., Conte, L.}

9. Cheon, S. H., y Reeve, J. (2013): Do the benefits from autonomy-supportive PE teacher training programs endure? A one-year follow-up investigation. Psychology of Sport and Exercise, 14 , 508-518.

doi:

10.1016/j.psychsport.2013.02.002

10. Cheon, S. H., y Reeve, J. (2015). A classroombased intervention to help teachers decrease students' amotivation. Contemporary Educational Psychology, 40, 99-111. doi: 10.1016/j.cedpsych.2014.06.004

11. Cheon, S. H., Reeve, J., Lee, Y, y Lee, J. (2018). Why autonomy-supportive interventions work: Explaing the professional development of teachers' motivating style. Teaching and Teacher Education, 69, 43-51. doi: 10.1016/j.tate.2017.09.022

12. Cheon, S. H., Reeve, J., y Moon, I. S. (2012). Experimentally based, longitudinally designed, teacher-focused intervention to help physical education teachers be more autonomy supportive toward their students. Journal of Sport \& Exercise Psychology, 34, 365-396. doi: 10.1123/jsep.34.3.365

13. Cheon, S. H., Reeve, J., y Ntoumanis, N. (2018). A needs-supportive intervention to help PE teachers enhance students' prosocial behavior and diminish antisocial behavior. Psychology of Sport \& Exercise, 35, 74-88. doi: 10.1016/j.psychsport.2017.11.010

14. De Meyer, J., Soenens, B., Vansteenkiste, M., Aelterman, N., Van Petegem, S., y Haerens, L. (2016). Do students with different motives for physical education respond differently to autonomy-supportive and controlling teaching? Psychology of Sport \& Exercise, 22, 72-82. doi: 10.1016/j.psychsport.2015.06.001

15. De Meyer, J., Tallir, I. B., Soenens, B., Vansteenkiste, M., Aelterman, N., Van den Berghe, L., . . . Haerens, L. (2014). Does observed controlling teaching behavior relate to students' motivation in physical education? Journal of Educational Psychology, 106(2), 541-554. doi: 10.1037/a0034399

16. Deci, E. L., y Ryan, R. M. (1980). The empirical exploration of intrinsic motivational processes. En L. Berkowitz (Ed.), Advances in experimental social psychology (Vol.13., pp. 39-80). New York: Academic Press.
17. Deci, E. L., y Ryan, R. M. (1985). Intrinsic motivation and self-determination in human behavior. New York, NY: Plenum.

18. Deci, E. L., y Ryan, R. M. (1991). A motivational approach to self: Integration in personality. In R. Dienstbier (Ed.), Nebraska symposium on motivation: Perspectives on motivation (Vol. 38, pp. 237-288). Lincoln: University of Nebraska Press.

19. Deci, E. L., y Ryan R. M. (2002). Handbook of self-Determination research. New York: The University of Rochester Press.

20. Deci, E. L., Schwartz, A. J., Sheinman, L., y Ryan, R. M. (1981). An instrument to assess adults' orientations toward control versus autonomy with children: Reflections on intrinsic motivation and perceived competence. Journal of Educational Psychology, 73(5), 642-650. doi: 10.1037/00220663.73.5.642

21. Digelidis, N., Papaioannou, A. Laparidis, K., y Christodoulidis, T. (2003). A one-year intervention in 7 th grade physical education classes aiming to change motivational climate and attitudes toward exercise. Psychology of Sport and Exercise, 4, 195-210. doi: 10.1016/S14690292(02)00002-X

22. Escriva-Boulley, G., Tessier, D., Ntoumanis, N., y Sarrazin, P. (2018). Need-supportive professional development in elementary school physical education: Effects of a cluster-randomized control trial on teachers' motivating style and student physical activity. Sport, Exercise, and Performance Psychology, 7(2), 218-234. doi: 10.1037/spy0000119

23. Gillet, N., Rosnet, E. y Vallerand, R. J. (2008). Développement d'une échelle de satisfaction des besoins fondamentaux en contexte sportif. Canadian Journal of Behavioural Science, 40(4), 230-237. doi:10.1037/a0013201

24. Gordon-Larsen, P., Nelson, M. C., y Popkin, B. M. (2004). Longitudinal physical activity and sedentary behavior trends: Adolescence to adulthood. American Journal of Preventive Medicine, 27(4), 277-283. doi: 10.1016/j.amepre.2004.07.006

25. Goudas, M., Biddle, S., y Fox, K. (1994). Perceived locus of causality, goal orientations, and perceived competence in school physical education classes. British Journal of Educational 


\section{Protocolo de apoyo a la autonomía en educación física}

Psychology, 64, 453-463. doi: 10.1111/j.20448279.1994.tb01116.x

26. Consejo Superior de Deportes. (2008). Grupo de trabajo de la Unión Europea, Deporte y Salud. Directrices de actividad fisica de la UE. Actuaciones recomendadas para apoyar la actividad fisica que promueve la salud. Madrid, España: CSD.

27. Haerens, L., Aelterman, N., Van der Berghe, L., De meyer, J., Soenens, B., y Vansteenkiste, M. (2013). Observing physical education teacher's need-supportive interactions in classroom settings. Journal of Sport and Exercise Psychology, 35, 3-17. doi: 10.1123/jsep.35.1.3

28. Hagger, M. S., Keatley, D., Chan D. y Derwin (2014). CALO-RE taxonomy of behavior change techniques. En Encyclopedia of sport and exercise psychology. R. C. Eklund, y G. T. Tenenbaum (Eds.), Encyclopedia of Sport and Exercise Psychology (pp. 100-105). Thousand Oaks: CA.

29. Hagger, M., Chatzisarantis, N. L., Hein, V., Soós, I., Karsai, I., Lintunen, T., y Leemans, S. (2009). Teacher, peer and parent autonomy support in physical education and leisure-time physical activity: A trans-contextual model of motivation in four nations. Psychology \& Health, 24(6), 689711. doi: 10.1080/08870440801956192

30. Hancox, J. E., Ntoumanis, N., ThøgersenNtoumani, C., y Quested, E. (2015a). Selfdetermination theory. En J. MiddelKamp (Ed.), EuropeActive's Essentials of motivation and behaviour change for fitness, health and sport professionals (pp. 68-84). Nijmegen: BlackBox Publishers.

31. Hancox, J. E., Quested, E., Thøgersen-Ntoumani, C., y Ntoumanis, N. (2015b). An intervention to train group exercise class instructors to adopt a motivationally adaptive communication style: a quasi-experimental study protocol. Health Psychology \& Behavioural Medicine, 3(1), 190203. doi: 10.1080/21642850.2015.1074075

32. Hein, V., Müür, M., y Koka, A. (2004). Intention to be physically active after school graduation and its relationship to three types of intrinsic motivation. European Physical Education Review, $\quad 10, \quad 5-19 . \quad$ doi: 10.1177/1356336X04040618

33. Hernández, J., Velázquez, R., Martínez, M., E., Garoz, I., López, C., y López, A. (2008). Frecuencia de actividad física en niños $y$ adolescentes: relación con su percepción de autoeficacia motriz, la práctica de su entorno social y su satisfacción con la Educación Física. Infancia y Aprendizaje, 31(1), 79-92. doi: 10.1174/021037008783487129

34. Jang, H., Reeve, J., y Halusic, M. (2016). A new autonomy-supportive way of teaching that increases conceptual learning: teaching in students' preferred ways. The Journal of Experimental Education, 84(4), 686-701. doi: 10.1080/00220973.2015.1083522

35. León, J., Domínguez, E., Nuñez, J. L., Pérez, A., y Martín-Albo, J. (2011). Traducción y validación de la versión española de la Échelle de Satisfacción des Besoins Psychologiques en el contexto educativo. Anales de Psicología, 27(2), 405-411.

36. Leptokaridou, E., Vlachopoulos, S., y Papaioannou, A. (2014). Experimental longitudinal test of the influence of autonomysupportive teaching on motivation for participation in elementary school physical education. Educational Psychology, 36(7), 11381159 .

https://doi.org/10.1080/01443410.2014.950195

37. Lonsdale, C., Lester, A., Owen, K. B., White, R. L., Moyes, I., Peralta, L., ... y Kolt, G. S. (2016). An internet-supported physical activity intervention delivered in secondary schools located in low socio-economic status communities: Study protocol for the Activity and Motivation in Physical Education (AMPED) Cluster Randomized Controlled Trial. $B M C$ Public Health, 16-17. doi: 10.1186/s12889-0152583-7

38. Michie, S., Ashford, S., Sniehotta, F. F., Dombrowski, S. U., Bishop, A., y French, D. P. (2011). A refined taxonomy of behaviour change techniques to help people change their physical activity and healthy eating behaviours: The CALO-RE taxonomy. Psychology and Health, 26, 1479-1498. doi:10.1080/ 08870446.2010.540664

39. Moore, G., Audrey, S., Barker, M., Bond, L., Bonell, C., Hardeman, W., y Baird, J. (2014). Process evaluation of complex interventions: Medical research council guidance. London: MRC Population Health Science Research.

40. Moreno, J. A., Moreno, R., y Cervelló, E. (2007). El autoconcepto físico como predictor de la 


\section{Moreno-Murcia, J. A., Huéscar, E., Nuñez, J. L., León, J., Valero-Valenzuela, A., Conte, L.}

intención de ser físicamente activo. Psicología y Salud, 17(2), 261-267.

41. Moreno, J. A., González-Cutre, D., y Chillón, M. (2009). Preliminary validation in Spanish of a scale designed to measure motivation in physical education classes: The Perceived Locus of Causality (PLOC) Scale. The Spanish Journal of Psychology, 12(1), 327-337. doi: $10.1017 / \mathrm{S} 1138741600001724$

42. Moreno, J. A., González-Cutre, D., Chillón, M., y Parra, N. (2008). Adaptación a la educación física de la escala de las necesidades psicológicas básicas en el ejercicio. Revista Mexicana de Psicología, 25(2), 295-303.

43. Moreno-Murcia, J. A., y Corbí, M. (en prensa). Apoyo social del docente y perfil motivacional en Educación Superior. Estudios de Educación.

44. Moreno-Murcia, J.A., Gea-Escámez, A. y Corbí, M. (2018). Predicción de la percepción de actividad física de los hijos a partir de la creencia de habilidad de los padres. Cuadernos de Psicología del Deporte, 18(3), 1-11.

45. Ng, J., Ntoumanis, N., Ntoumanis, C., Deci, E., Ryan, R., Duda, J. L., y Williams, G. C. (2012). Self-determination theory applied to health contexts: A meta-analysis. Perspectives on Psychological Science, 7(4), 325-340. doi: 10.1177/1745691612447309

46. Ntoumanis, N., Thøgersen-Ntoumani, C., Quested, E., y Hancox, J. (2016). The effects of training group exercise class instructors to adopt a motivationally adaptive communication style. Scandinavian Journal of Medicine \& Science in Sports, 27, 1026-1034. doi: 10.1111/sms.12713

47. Núñez, J. L., Martín-Albo, J., y Navarro, J. G. (2005). Validación de la versión española de la Échelle de Motivation en Éducation. Psicothema, 17(2), 344-349.

48. Organización Mundial de la Salud (2016, junio). Obesidad y sobrepeso. Recuperado de: http://www.who.int/mediacentre/factsheets/fs311 /es/

49. Pelletier, L. G., Beaudry, S., Sharp, E., y Otis, N. (2008). The Interpersonal Behaviors Scale: A measure of autonomy support, competence and relatedness in different life domains. Manuscrito no publicado. Universidad of Ottawa, Ontorio, Canadá.

50. Pelletier, L. G., Séguin-Lévesque, L., y Legault, L. (2002). Pressure from above and pressure from below as determinants of teachers' motivation and teaching behaviors. Journal of Educational Psychology, 94(1), 186-196.

51. Perlman, D. (2015). Assisting preservice teachers toward more motivationally supportive instruction. Journal of Teaching in Physical Education, 34(1), 119-130. doi: 10.1123/jtpe.2013-0208

52. Poletti, O. H., y Barrios, L. (2007). Sobrepeso, obesidad, hábitos alimentarios, actividad física y uso del tiempo libre en escolares de Corrientes (Argentina). Revista Cubana de Pediatría, 79, 1.

53. Reeve, J. (2009). Why teachers adopt a controlling motivating style towards students and how the can be more autonomy supportive? Educational Psychologist, 44(3), 159-175. doi: 10.1080/00461520903028990

54. Reeve, J., y Jang, H. (2006). What teachers say and do to support students' autonomy during a learning activity. Journal of Educational Psychology, 98, 209-218. doi: 10.1037/00220663.98.1.209

55. Reeve, J., y Cheon, H. S. (2014). An interventionbased program of research on teachers' motivating styles. En S. A. Karabenick, y T. C. Urdan (Eds.), Advances in motivation and achievement: Motivational interventions (Vol. 18, pp. 293-339). Bingley, United Kingdom: Emerald Group Publishing.

56. Reeve, J., y Cheon, S. (2016): Teachers become to be more supportive-autonomy after they believe it is easy to do. Psychology of Sport and Exercise, 22, 178-189 doi: 10.1016/j.psychsport.2015.08.001

57. Reeve, J., y Tseng, C. M. (2011). Cortisol reactivity to teacher's motivating style: The biology of being controlled versus supporting autonomy. Motivation and Emotion, 35, 63-74. doi: 10.1007/s11031-011-9204-2

58. Reeve, J., Vansteenkiste, M., Assor, A., Ahmad, I., Cheon, S. H., Jang, H., y Wang, C. J. (2014). The beliefs that underlie autonomy-supportive and controlling teaching: A multinational investigation. Motivation and Emotion, 38(1), 93110. doi: 10.1007/s11031-013-9367-0

59. Ryan, R. M., y Deci, E. L., (2000): Selfdetermination Theory and the facilitation of the intrinsic motivation, social development, and well-being. American Psychologist, 55(1), 68-78. doi: 10.1037/0003-066X.55.1.68 


\section{Protocolo de apoyo a la autonomía en educación física}

60. Ryan, R. M., y Deci, E. L. (2002). An overview of Self-determination Theory: An organismicdialectical perspective. En E. L. Deci y R. M. Ryan (Eds.), Handbook of self-determination research (pp. 3-33). Rochester, NY: The University of Rochester Press.

61. Sarrazin, P., Tessier, D., Pelletier, L., Trouilloud, D. y Chanal, J. (2006). The Effects of Teachers' Expectations about Students' Motivation On Teachers Autonomy-Supportive and Controlling Behaviors. International Journal of Sport and Exercise Psychology, Taylor \& Francis, 4, 283301 .

62. Tessier, D., Sarrazin, P., y Ntoumanis, N. (2008). The effects of an experimental programme to support student's autonomy on the overt behaviours of physical education teachers. European Journal of Psychology of Education, 3, 239-253. doi: 10.1007/BF03172998

63. Tessier, D., Sarrazin, P., y Ntoumanis, N. (2010). The effect of an intervention to improve newly qualified teachers' interpersonal style, students' motivation and psychological need satisfaction in sport-based physical education. Contemporary Educational Psychology, 35, 242-253. doi: 10.1016/j.cedpsych.2010.05.005

64. Trost, S. G., y Loprinzi, P. D. (2008). ExercisePromoting healthy lifestyles in children and adolescents. Journal of Clinical Lipidology, 2(3), 162-168. doi: 10.1016/j.jacl.2008.03.001

65. Su, Y. L., y Reeve, J. (2011). A meta-analysis of the effectiveness of intervention programs designed to support autonomy. Educational Psychology Review, 23, 159-188. doi: 10.1007/s10648-010-9142-7

66. Vallerand, R. J. (1997). Toward a hierarchical model of intrinsic and extrinsic motivation. En M.P. Zanna (Ed.), Advances in experimental social psychology (pp. 271-360). San Diego. Academic Press.

67. Vallerand, R.J., Blais, M.R., Brière, N.M. y Pelletier, L.G. (1989). Construction et validation de l'Échelle de Motivation en Éducation (EME). Canadian Journal of Behavioral Sciences, 21, 323-349.

68. Van de Berghe, L., Soenens, B., Vansteenkiste, M., Aelterman, N., Cardon, G., Tallir, I. B., y Haerens, L. (2013). Observed need-supportive and need-thwarting teaching behavior in physical education: Do teachers' motivational orientations matter? Psychology of Sport and Exercise, 14, 650-661. doi:10.1016/j. psychsport.2013.04.006

69. Varo-Cenarruzabeitia, J. J., y Martínez-González, M. A. (2006). El consejo sanitario en la promoción de la actividad física. Medicina Clínica, 62, 37-42. doi: $10.1157 / 13086057$

70. Vlachopoulos, S. P., y Michailidou, S. (2006). Development and initial validation of a measure of autonomy, competence and relatedness in exercise: The Basic Psychological Needs in Exercise Scale. Measurement in Physical Education and Exercise Science, 10, 179-201. doi:10.1207/s15327841mpee1003_4

71. Yew, M., y Wang, K. (2016). The effectiveness of an Autonomy-Supportive Teaching Structure in Physical Education. RICYDE. Revista Internacional de Ciencias del Deporte, 12(43), 528. doi: 10.5232/ricyde2016.04301 
Moreno-Murcia, J. A., Huéscar, E., Nuñez, J. L., León, J., Valero-Valenzuela, A., Conte, L.
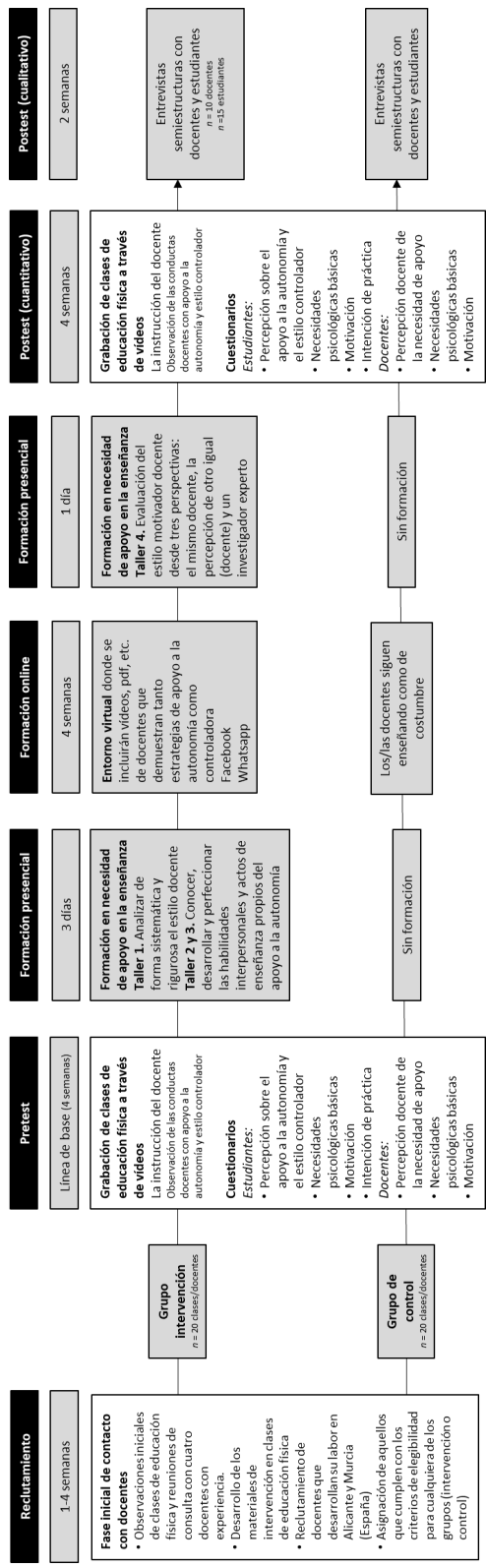

Figura 1. Descripción general del diseño del estudio y sus principales componentes 


\section{Protocolo de apoyo a la autonomía en educación física}

Tabla 1. Definición, características y conductas didácticas del estilo controlador, neutro y de apoyo a la autonomía docente (Modificado de Reeve, 2009; Sarrazin, Tessier, Pelletier, Trouilloud, y Chanal, 2006)

\begin{tabular}{|c|c|c|}
\hline Control & Neutro & $\begin{array}{l}\text { Apoyo a la } \\
\text { autonomía }\end{array}$ \\
\hline \multicolumn{3}{|c|}{ Definición } \\
\hline $\begin{array}{l}\text { Conducta } \\
\text { interpersonal docente } \\
\text { que se proporciona } \\
\text { durante la enseñanza } \\
\text { para presionar a los } \\
\text { estudiantes a pensar, } \\
\text { sentir o comportarse } \\
\text { de una manera } \\
\text { específica. }\end{array}$ & $\begin{array}{l}\text { Conducta interpersonal } \\
\text { docente que se proporciona } \\
\text { durante la enseñanza que } \\
\text { solo informa y no afecta en } \\
\text { el comportamiento del } \\
\text { alumnado. }\end{array}$ & $\begin{array}{l}\text { Conducta } \\
\text { interpersonal } \\
\text { docente que se } \\
\text { proporciona durante } \\
\text { la enseñanza para } \\
\text { identificar, nutrir y } \\
\text { desarrollar los } \\
\text { recursos } \\
\text { motivacionales } \\
\text { internos de los } \\
\text { estudiantes. }\end{array}$ \\
\hline \multicolumn{3}{|c|}{ Características } \\
\hline $\begin{array}{l}\text { - Adoptar la } \\
\text { perspectiva del } \\
\text { docente. } \\
\text { - Entrometerse en los } \\
\text { pensamientos, } \\
\text { sentimientos o } \\
\text { acciones de los } \\
\text { estudiantes. } \\
\text { - Presionar a los } \\
\text { estudiantes a } \\
\text { pensar, sentir o } \\
\text { comportarse de } \\
\text { una manera } \\
\text { específica. }\end{array}$ & $\begin{array}{l}\text { - Adoptar una perspectiva } \\
\text { ambigua durante la } \\
\text { instrucción. } \\
\text { - No se compromete en } \\
\text { pensamiento y se } \\
\text { mantiene al margen. } \\
\text { - No presionar pero no } \\
\text { motivar. }\end{array}$ & $\begin{array}{l}\text { - Adoptar la } \\
\text { perspectiva del } \\
\text { estudiante. } \\
\text { - Respetar los } \\
\text { pensamientos, } \\
\text { sentimientos y } \\
\text { acciones de los } \\
\text { estudiantes } \\
\text { - Motivar a los } \\
\text { estudiantes para } \\
\text { desarrollar la } \\
\text { capacidad de } \\
\text { pensar de forma } \\
\text { autónoma. }\end{array}$ \\
\hline \multicolumn{3}{|c|}{ Conductas didácticas } \\
\hline $\begin{array}{l}\text { - Recurrir a fuentes } \\
\text { externas de } \\
\text { motivación. } \\
\text { - Razonamientos } \\
\text { explicativas no } \\
\text { resolutivos. } \\
\text { - Confiar en un } \\
\text { lenguaje que } \\
\text { induce a la } \\
\text { presión. } \\
\text { - Mostrar } \\
\text { impaciencia para } \\
\text { que los estudiantes } \\
\text { produzcan las } \\
\text { respuestas } \\
\text { correctas. } \\
\text { - Reafirmarse en su } \\
\text { autoridad y poder } \\
\text { para anular las } \\
\text { quejas y } \\
\text { manifestaciones } \\
\text { negativas de los } \\
\text { estudiantes. }\end{array}$ & $\begin{array}{l}\text { - Emplear fuentes/recursos } \\
\text { aleatorios para motivar } \\
\text { - Utilizar razonamientos } \\
\text { explicativos ambiguos. } \\
\text { - Adoptar un lenguaje que } \\
\text { no es cercano pero } \\
\text { tampoco induce a la } \\
\text { presión (o viceversa). } \\
\text { - Seguir con las actividades } \\
\text { programadas sin mostrar } \\
\text { presión o paciencia por } \\
\text { los ritmos de los } \\
\text { estudiantes. } \\
\text { - Apoyarse en la } \\
\text { programación/contenido } \\
\text { para justificar o reafirmar } \\
\text { su autoridad. }\end{array}$ & $\begin{array}{l}\text { - Cultivar recursos } \\
\text { motivacionales } \\
\text { internos. } \\
\text { - Proporcionar } \\
\text { razonamientos } \\
\text { explicativos. } \\
\text { - Adoptar un } \\
\text { lenguaje no } \\
\text { controlador. } \\
\text { - Mostrar paciencia } \\
\text { respetando el } \\
\text { ritmo de } \\
\text { aprendizaje } \\
\text { individual del } \\
\text { estudiante. } \\
\text { - Reconocer y } \\
\text { aceptar las } \\
\text { expresiones de } \\
\text { afecto negativo. }\end{array}$ \\
\hline
\end{tabular}




\section{Moreno-Murcia, J. A., Huéscar, E., Nuñez, J. L., León, J., Valero-Valenzuela, A., Conte, L.}

Tabla 2. Estrategias para el estilo interpersonal de apoyo a la autonomía.

\begin{tabular}{lll}
\hline Descripción del contexto & Estrategia autónoma & Estrategia controladora \\
\hline $\begin{array}{l}\text { En el transcurso de la clase cuando el docente } \\
\text { propone una situación de enseñanza-aprendizaje... }\end{array}$ & $\begin{array}{l}\text { Pregunta al estudiante sobre sus preferencias } \\
\text { en relación a una tarea. }\end{array}$ & $\begin{array}{l}\text { No pregunta ni tiene en cuenta las } \\
\text { preferencias del estudiante. }\end{array}$ \\
\hline $\begin{array}{l}\text { En el desarrollo de la clase, el docente cuando } \\
\text { plantea las tareas... }\end{array}$ & $\begin{array}{l}\text { Ofrece posibilidad de elección al estudiante } \\
\text { (agrupaciones, materiales y espacios). }\end{array}$ & $\begin{array}{l}\text { No ofrece elección al estudiante. Todo está } \\
\text { definido previamente por el criterio del } \\
\text { docente. }\end{array}$ \\
\hline $\begin{array}{l}\text { En el planteamiento de las tareas, sobre la toma de } \\
\text { decisiones de los estudiantes a cerca de su } \\
\text { intervención, el docente... }\end{array}$ & $\begin{array}{l}\text { Deja que el estudiante tome la iniciativa } \\
\text { (cede la iniciativa). }\end{array}$ & $\begin{array}{l}\text { No cede la iniciativa. Les informa sobre } \\
\text { cuándo ejecutar las tareas sin dejar opción. }\end{array}$ \\
\hline $\begin{array}{l}\text { El docente, sobre la posibilidad del afianzamiento, } \\
\text { ampliación o reforzamiento de los objetivos } \\
\text { perseguidos con las tareas... }\end{array}$ & $\begin{array}{l}\text { Ofrece posibilidades de experimentación } \\
\text { (individualiza la enseñanza). }\end{array}$ & $\begin{array}{l}\text { Propone tareas cerradas y anticipa las } \\
\text { respuestas. }\end{array}$ \\
\hline $\begin{array}{l}\text { El docente, cuando organiza tareas, manifiesta } \\
\text { expectativas hacia el grupo de forma que... }\end{array}$ & $\begin{array}{l}\text { Cede responsabilidad manifestando sus } \\
\text { expectativas positivas y confianza en que } \\
\text { saldrá bien. }\end{array}$ & $\begin{array}{l}\text { No cede responsabilidad, genera presión } \\
\text { emocional e inhibe al estudiante. }\end{array}$ \\
\hline
\end{tabular}

Tabla 3. Estrategias para el estilo interpersonal de apoyo a la estructura antes y durante la tarea.

\begin{tabular}{|c|c|c|c|}
\hline \multicolumn{4}{|l|}{ Antes de la tarea } \\
\hline Descripción del contexto & Estrategia autónoma & Estrategia controladora & Estrategia neutra \\
\hline $\begin{array}{l}\text { Respecto a la información que } \\
\text { da el docente a los estudiantes } \\
\text { antes de iniciar una tarea... }\end{array}$ & $\begin{array}{l}\text { Al iniciar la tarea explica y } \\
\text { relaciona la misma con los } \\
\text { objetivos de la clase. }\end{array}$ & $\begin{array}{l}\text { No relaciona los objetivos de la } \\
\text { tarea con la clase y se centra en el } \\
\text { contenido. }\end{array}$ & \\
\hline $\begin{array}{l}\text { Antes de comenzar la práctica, } \\
\text { el docente, sobre la posibilidad } \\
\text { de ubicar esa tarea dentro de la } \\
\text { estructura de la clase... }\end{array}$ & $\begin{array}{l}\text { Ubica la tarea dentro de la } \\
\text { estructura de la clase } \\
\text { (organización). }\end{array}$ & $\begin{array}{l}\text { No ubica la tarea dentro de la } \\
\text { estructura de la clase previamente. } \\
\text { Llegado el momento, expone las } \\
\text { tareas y asigna a los estudiantes. }\end{array}$ & \\
\hline $\begin{array}{l}\text { El docente ofrece argumentos } \\
\text { sobre la transferencia social que } \\
\text { tiene la realización de una } \\
\text { actividad... }\end{array}$ & Explica la utilidad de las tareas. & $\begin{array}{l}\text { No explica la utilidad de las tareas } \\
\text { y se centra en la ejecución. }\end{array}$ & \\
\hline $\begin{array}{l}\text { El docente, cuando necesita } \\
\text { ilustrar antes de empezar la } \\
\text { clase... }\end{array}$ & $\begin{array}{l}\text { Se apoya en los estudiantes como } \\
\text { modelos positivos para realizar } \\
\text { demostraciones. }\end{array}$ & $\begin{array}{l}\text { No se apoya en los estudiantes, el } \\
\text { docente es el modelo a imitar. }\end{array}$ & \\
\hline $\begin{array}{l}\text { Cuando se presenta una tarea, } \\
\text { sobre la posibilidad de orientar } \\
\text { sobre la mejora personal con } \\
\text { criterios para el estudiante, el } \\
\text { docente... }\end{array}$ & $\begin{array}{l}\text { Lo hace ofreciendo pautas y } \\
\text { orientaciones para regular el } \\
\text { progreso personal y da a conocer } \\
\text { previamente los criterios de } \\
\text { mejora. }\end{array}$ & $\begin{array}{l}\text { No ofrece pautas ni orientaciones } \\
\text { a modo de indicador de mejora. }\end{array}$ & \\
\hline \multicolumn{4}{|l|}{ Durante la tarea } \\
\hline $\begin{array}{l}\text { El docente durante la ejecución } \\
\text { de las actividades... }\end{array}$ & $\begin{array}{l}\text { Adapta las instrucciones según el } \\
\text { progreso de los estudiantes. }\end{array}$ & $\begin{array}{l}\text { Mantiene constantes las } \\
\text { informaciones, con independencia } \\
\text { del progreso (empleando un } \\
\text { lenguaje controlador). }\end{array}$ & $\begin{array}{l}\text { El docente únicamente describe la } \\
\text { situación sin aludir a los } \\
\text { participantes sin promover el } \\
\text { progreso ni emplear un lenguaje } \\
\text { controlador. }\end{array}$ \\
\hline $\begin{array}{l}\text { El docente cuando necesita } \\
\text { ilustrar las tareas una vez } \\
\text { iniciadas... }\end{array}$ & $\begin{array}{l}\text { Utiliza a modelos a través de } \\
\text { estudiantes. }\end{array}$ & $\begin{array}{l}\text { Utiliza los modelos a través de } \\
\text { estudiantes y emplea un lenguaje } \\
\text { controlador (emplea un tono que } \\
\text { evidencia menosprecio). }\end{array}$ & $\begin{array}{l}\text { Utiliza modelos sin aportar } \\
\text { información, ni positiva ni } \\
\text { negativa. }\end{array}$ \\
\hline $\begin{array}{l}\text { Sobre si el docente participa en } \\
\text { las explicaciones de las tareas... }\end{array}$ & $\begin{array}{l}\text { Cuando es necesario comparte } \\
\text { con los estudiantes las } \\
\text { demostraciones. }\end{array}$ & $\begin{array}{l}\text { No participa en las } \\
\text { demostraciones. Las dirige usando } \\
\text { lenguaje controlador. }\end{array}$ & $\begin{array}{l}\text { No participa en las } \\
\text { demostraciones e interviene sin } \\
\text { informar al respecto. }\end{array}$ \\
\hline
\end{tabular}

Cuadernos de Psicología del Deporte, 19, 2 (mayo) 


\section{Protocolo de apoyo a la autonomía en educación física}

\begin{tabular}{|c|c|c|c|}
\hline $\begin{array}{l}\text { Sobre las variantes que puede } \\
\text { ofrecer el docente durante el } \\
\text { desarrollo de una tarea... }\end{array}$ & $\begin{array}{l}\text { Recuerda las diferentes variantes } \\
\text { para una misma tarea. }\end{array}$ & $\begin{array}{l}\text { No ofrece variantes para una } \\
\text { misma tarea, sino que va } \\
\text { imponiendo su visión como única } \\
\text { opción. }\end{array}$ & \\
\hline $\begin{array}{l}\text { Durante la realización de las } \\
\text { tareas, el docente... }\end{array}$ & $\begin{array}{l}\text { Ofrece refuerzos positivos tanto } \\
\text { verbales como no verbales. } \\
\text { Anima a los estudiantes a que } \\
\text { perseveren. }\end{array}$ & $\begin{array}{l}\text { Destaca y penaliza las ejecuciones } \\
\text { incorrectas. }\end{array}$ & $\begin{array}{l}\text { Se limita a describir una situación } \\
\text { sin emplear un lenguaje } \\
\text { controlador. Las interacciones que } \\
\text { proporciona no son positivas ni } \\
\text { negativas. }\end{array}$ \\
\hline $\begin{array}{l}\text { El docente, durante el desarrollo } \\
\text { de las actividades... }\end{array}$ & $\begin{array}{l}\text { Ofrece feed-back informativo y/o } \\
\text { positivo durante la ejecución de } \\
\text { las tareas. }\end{array}$ & $\begin{array}{l}\text { No ofrece feed-back informativo } \\
\text { ni positivo, únicamente negativo. }\end{array}$ & $\begin{array}{l}\text { Ofrece feed-back neutro y } \\
\text { ambiguo que no aporta nada sobre } \\
\text { el desarrollo de la acción. }\end{array}$ \\
\hline $\begin{array}{l}\text { El docente plantea las } \\
\text { actividades habitualmente de } \\
\text { forma que... }\end{array}$ & $\begin{array}{l}\text { Ofrece una graduación de la } \\
\text { dificultad de las tareas según el } \\
\text { nivel de los estudiantes. }\end{array}$ & $\begin{array}{l}\text { Gradúa la dificultad de las tareas } \\
\text { según a la norma y no al nivel del } \\
\text { estudiante. }\end{array}$ & \\
\hline $\begin{array}{l}\text { En el transcurso de las } \\
\text { actividades, el docente... }\end{array}$ & $\begin{array}{l}\text { Propone agrupaciones flexibles } \\
\text { según el desarrollo de las tareas. }\end{array}$ & $\begin{array}{l}\text { No fomenta agrupaciones } \\
\text { flexibles. }\end{array}$ & \\
\hline
\end{tabular}

Tabla 4. Estrategias para el estilo interpersonal de apoyo a la relación.

\begin{tabular}{|c|c|c|c|}
\hline Descripción del contexto & Estrategia autónoma & Estrategia controladora & Estrategia neutra \\
\hline $\begin{array}{l}\text { Durante el desarrollo de la } \\
\text { sesión, el docente... }\end{array}$ & $\begin{array}{l}\text { Se dirige a los estudiantes con } \\
\text { educación y de manera } \\
\text { individualizada. }\end{array}$ & $\begin{array}{l}\text { Se dirige a los estudiantes en gran } \\
\text { grupo de forma imperativa. }\end{array}$ & $\begin{array}{l}\text { Se dirige a los estudiantes en gran } \\
\text { grupo empleando un lenguaje } \\
\text { impersonal, inespecífico. }\end{array}$ \\
\hline $\begin{array}{l}\text { El docente en clase cuando se } \\
\text { dirige a los estudiantes... }\end{array}$ & Emplea un lenguaje empático. & $\begin{array}{l}\text { No emplea un lenguaje empático y } \\
\text { no se adapta al estudiante. }\end{array}$ & $\begin{array}{l}\text { Utiliza un lenguaje apático cuando se } \\
\text { dirige a los estudiantes (sin emoción, } \\
\text { no aporta nada ni positivo ni negativo). }\end{array}$ \\
\hline $\begin{array}{l}\text { Cuando los estudiantes se } \\
\text { dirigen al docente, éste... }\end{array}$ & $\begin{array}{l}\text { Escucha a los estudiantes con } \\
\text { actitud activa y positiva. }\end{array}$ & $\begin{array}{l}\text { No tiene una actitud de escucha } \\
\text { activa reprochando la petición de } \\
\text { ayuda del estudiante. }\end{array}$ & $\begin{array}{l}\text { Les escucha pero no atiende a sus } \\
\text { dudas o las pospone. }\end{array}$ \\
\hline $\begin{array}{l}\text { El docente durante el desarrollo } \\
\text { de la clase... }\end{array}$ & $\begin{array}{l}\text { Se aproxima al estudiante } \\
\text { para atenderle. }\end{array}$ & $\begin{array}{l}\text { No se aproxima para atender a los } \\
\text { estudiantes. }\end{array}$ & \\
\hline $\begin{array}{l}\text { El docente cuando interactúa en } \\
\text { clase... }\end{array}$ & Es entusiasta. & No muestra entusiasmo. & Ni muestra entusiasmo ni indiferencia. \\
\hline $\begin{array}{l}\text { El docente durante el desarrollo } \\
\text { de la clase... }\end{array}$ & $\begin{array}{l}\text { Da confianza a los } \\
\text { estudiantes. }\end{array}$ & $\begin{array}{l}\text { No da confianza y genera } \\
\text { inseguridad en clase. }\end{array}$ & \\
\hline $\begin{array}{l}\text { El docente durante el desarrollo } \\
\text { de la clase... }\end{array}$ & $\begin{array}{l}\text { Se comporta como un modelo } \\
\text { positivo para los estudiantes. }\end{array}$ & $\begin{array}{l}\text { No se comporta como un modelo } \\
\text { positivo para los estudiantes. }\end{array}$ & $\begin{array}{l}\text { No se comporta ni positiva ni } \\
\text { negativamente, guarda silencio } \\
\text { mientras los participantes ejecutan la } \\
\text { tarea y si interviene lo hace para } \\
\text { describir algo que está fuera de la } \\
\text { ejecución, como las repeticiones o el } \\
\text { tiempo que llevan o falta para terminar. }\end{array}$ \\
\hline
\end{tabular}

Tabla 5. Adaptación de las técnicas de cambio de comportamiento CALO-RE (Hagger et al., 2014; Hancox et al., 2015a; Michie et al., 2011) que se aplicarán en el programa de formación con apoyo a la autonomía en educación física 
Moreno-Murcia, J. A., Huéscar, E., Nuñez, J. L., León, J., Valero-Valenzuela, A., Conte, L.

\begin{tabular}{|c|c|c|}
\hline $\begin{array}{l}\text { Definición de técnicas } \\
\text { para el cambio } \\
\text { comportamental }\end{array}$ & Objetivo & Actividad modelo \\
\hline $\begin{array}{l}\text { 1. Dar información grupal } \\
\text { (general) }\end{array}$ & $\begin{array}{l}\text { Al iniciar las tareas explicar al grupo los } \\
\text { objetivos y la relación con las tareas propuestas, } \\
\text { así como su utilidad dentro de la estructura de la } \\
\text { clase (organización). Esta información también } \\
\text { estará disponible en los medios de información } \\
\text { disponible como Facebook, web, grupo de } \\
\text { Whatsapp y grabaciones en vídeo. Tendrá un } \\
\text { carácter interactivo entre todos los participantes } \\
\text { del taller. }\end{array}$ & $\begin{array}{l}\text { Utilizar los } 10 \text { primeros minutos de la clase para mostrar la } \\
\text { planificación de la clase y las tareas que la componen. } \\
\text { Debate grupal atendiendo a las dudas que puedan surgir. }\end{array}$ \\
\hline $\begin{array}{l}\text { 2. Dar información } \\
\text { individual }\end{array}$ & $\begin{array}{l}\text { Dar a conocer de forma individual durante los } \\
\text { talleres, por qué es beneficioso utilizar el apoyo } \\
\text { a la autonomía y qué tipo de información se } \\
\text { utiliza, así como las estrategias docentes } \\
\text { respecto a: autonomía, relaciones, percepción de } \\
\text { competencia. }\end{array}$ & $\begin{array}{l}\text { Lluvia de ideas sobre la conveniencia de utilizar estilos } \\
\text { centrados en el estudiante. } \\
\text { Mostrar de forma gráfica los beneficios que la literatura } \\
\text { científica recoge sobre las bondades del estilo interpersonal de } \\
\text { apoyo a la autonomía. } \\
\text { Debate y conclusión. }\end{array}$ \\
\hline
\end{tabular}

\begin{tabular}{ll}
\hline $\begin{array}{l}\text { 3. Beneficios relaciones } \\
\text { sociales }\end{array}$ & $\begin{array}{l}\text { Poner de manifiesto en las prácticas realizadas } \\
\text { las ventajas de la necesidad de relación } \\
\text { realizando actividades en las que pueden } \\
\text { vivenciar las relaciones sociales. }\end{array}$ \\
\hline $\begin{array}{l}\text { 4. Plantear objetivos } \\
\text { alcanzables medio plazo }\end{array}$ & $\begin{array}{l}\text { Proponer y experimentar en la práctica que las } \\
\text { metas se pueden conseguir. }\end{array}$ \\
\hline $\begin{array}{l}\text { 5. Planificación de la clase } \\
\text { con consecución } \\
\text { progresiva de las tareas }\end{array}$ & $\begin{array}{l}\text { Contribuir al conocimiento de las tareas de la } \\
\text { clase. Aumentar el protagonismo de los } \\
\text { practicantes a través de la cesión de autonomía. }\end{array}$
\end{tabular}

Diseño en grupo cooperativo de una tarea relativa a una estrategia a la autonomía.

Manifestar feed-back a los docentes del taller para alcanzar el reto. Preguntar y aceptar alguna propuesta de los docentes.

Al inicio de las tareas se informa sobre los objetivos a cumplir en la clase: indicando los momentos y detalles en que se da autonomía, pedir opiniones, iniciativa y variantes.

Dicha información también estará disponible en: vídeos, grupo de Facebook y WhatsAp, trabajando de modo interactivo y contrastando las experiencias con el grupo de expertos. Los expertos y educadores crearán hojas de registro y un plan de acción detallado sobre cómo van a poner en práctica las técnicas de apoyo a la autonomía y motivación.

\begin{tabular}{ll}
\hline 6. Identificación de & Identificar el problema y planificar como \\
barreras/resolución de & resolverlo. \\
problemas & Trabajar con tareas que por su naturaleza o \\
& modo de desarrollarse sean más fáciles de \\
& manejar y no propicien problemas de \\
& comportamiento o desmotivación.
\end{tabular}
Identificar las temáticas que el docente domine y de fácil control para adaptar objetivos, contenidos y poder solucionar las contingencias que puedan surgir. Anticipar problemas y ser capaz de flexibilizar adaptándose al alumnado.

\begin{tabular}{lll}
$\begin{array}{l}\text { 7. Revisión de los } \\
\text { objetivos de resultados }\end{array}$ & Revisar y comprobar si hay cierta mejora. & $\begin{array}{l}\text { Grabación en vídeo de las conductas con la ayuda de un } \\
\text { compañero para comprobar si se han cumplido los objetivos } \\
\text { concretos marcados. }\end{array}$ \\
\hline $\begin{array}{l}\text { 8. Valorar el esfuerzo de } \\
\text { la práctica }\end{array}$ & $\begin{array}{l}\text { Valorar el esfuerzo solo por el hecho de realizar } \\
\text { la práctica. }\end{array}$ & $\begin{array}{l}\text { Expresar feed-back motivador y de reconocimiento aunque no } \\
\text { se consigan los resultados, solo por el hecho de esforzarse. }\end{array}$ \\
\hline $\begin{array}{l}\text { 9. Dar feed-back o } \\
\text { recompensas por } \\
\text { conseguir logros de } \\
\text { conducta }\end{array}$ & $\begin{array}{l}\text { Proporcionar recompensas cuando algún } \\
\text { docente desempeñe exitosamente la conducta de } \\
\text { apoyo a la autonomía planteada como objetivo } \\
\text { para evitar el estancamiento. }\end{array}$ & $\begin{array}{l}\text { Durante el taller manifestar la recompensa verbal, y cuando el } \\
\text { enviado por Facebook o el grupo de Whatsapp, el feed-back } \\
\text { será a través de un texto escrito o mensaje de voz. }\end{array}$ \\
$\begin{array}{lll}\text { 10. Generalizar la } \\
\text { conducta objetivo }\end{array}$ & $\begin{array}{l}\text { Ampliar la mejoría detectada en una actividad a a } \\
\text { otros aspectos relacionados con la tarea y } \\
\text { ampliar los objetivos a conseguir. }\end{array}$ & $\begin{array}{l}\text { Recordar su competencia en un contexto para extrapolarla a } \\
\text { otro. }\end{array}$ \\
\hline $\begin{array}{l}\text { 11. Utilizar modelos de } \\
\text { conducta }\end{array}$ & $\begin{array}{l}\text { Para informar cuándo y dónde diferentes } \\
\text { estrategias podrían llevarse a la práctica } \\
\text { mediante el modelado, } \\
\text { identificar los elementos claves a conseguir en } \\
\text { forma de conductas observables. Proporcionar }\end{array}$ & $\begin{array}{l}\text { Modelado con un experto. } \\
\text { Con todo el material y soporte documental durante los talleres } \\
\text { se realizarán ejecuciones de apoyo a la autonomía por parte de } \\
\text { los expertos que reproducirán las conductas clave para el grupo. }\end{array}$ \\
\hline
\end{tabular}




\section{Protocolo de apoyo a la autonomía en educación física}

\begin{tabular}{|c|c|c|}
\hline & $\begin{array}{l}\text { pistas concretas que ayuden a mejorar las pautas } \\
\text { que se están trabajando. }\end{array}$ & \\
\hline $\begin{array}{l}\text { 12. El uso de mensajes de } \\
\text { seguimiento }\end{array}$ & $\begin{array}{l}\text { Utilizar diferentes medios como apoyo, que } \\
\text { aporte información respecto a elementos claves } \\
\text { de comportamiento o actuación. } \\
\text { Por ejemplo, después de los talleres, a través del } \\
\text { grupo de Facebook, cada semana, se facilitará a } \\
\text { los educadores 3-4 nuevas estrategias de apoyo } \\
\text { a la autonomía. }\end{array}$ & $\begin{array}{l}\text { Un compañero de un grupo puede dar información al resto a } \\
\text { través de un auricular. También la utilización de los grupos de } \\
\text { Whatsapp o de Facebook como un buen apoyo para dar claves } \\
\text { puntuales en determinados momentos. }\end{array}$ \\
\hline $\begin{array}{l}\text { 13. Facilitar la } \\
\text { comparación social }\end{array}$ & $\begin{array}{l}\text { Valorar los recursos utilizados y comparar con } \\
\text { los utilizados por uno mismo. }\end{array}$ & $\begin{array}{l}\text { Durante una tarea, utilizar a los estudiantes como modelos } \\
\text { positivos de aprendizaje para el profesorado. También, las } \\
\text { grabaciones en vídeo, grupo de Whatsapp, grupo de Facebook y } \\
\text { valoraciones de los compañeros son una gran ayuda. }\end{array}$ \\
\hline $\begin{array}{l}\text { 14. Contrato de } \\
\text { compromiso a querer } \\
\text { aprender un estilo } \\
\text { interpersonal de apoyo a la } \\
\text { autonomía }\end{array}$ & $\begin{array}{l}\text { Manifestar el deseo y compromiso de adoptar y } \\
\text { mantener el estilo interpersonal de apoyo a la } \\
\text { autonomía. }\end{array}$ & $\begin{array}{l}\text { Se pedirá a los docentes que firmen un contrato para llevar a } \\
\text { cabo una serie de acciones encaminadas a dominar un estilo de } \\
\text { apoyo a la autonomía. }\end{array}$ \\
\hline $\begin{array}{l}\text { 15. El uso oportuno de las } \\
\text { imágenes }\end{array}$ & $\begin{array}{l}\text { Priorizar el uso de imágenes (impacto visual) a } \\
\text { texto. }\end{array}$ & $\begin{array}{l}\text { Utilizar antes que un texto, una foto, imagen o signo, ya que } \\
\text { puede servir como referencia para recordar algo, y cumplir los } \\
\text { objetivos de la práctica. }\end{array}$ \\
\hline $\begin{array}{l}\text { 16. Fomentar el apoyo } \\
\text { social a través de las } \\
\text { habilidades de } \\
\text { comunicación }\end{array}$ & $\begin{array}{l}\text { Mejorar las habilidades de comunicación con el } \\
\text { fin de optimizar las interacciones con otras } \\
\text { personas. También se alentará a los docentes } \\
\text { para obtener apoyo social entre sí y utilizar el } \\
\text { grupo de Facebook para compartir experiencias. }\end{array}$ & $\begin{array}{l}\text { Actividad de role playing donde se compara el valor de } \\
\text { informar de un modo claro, breve y preciso que anime a la } \\
\text { práctica respetando las posibilidades de cada uno frente a un } \\
\text { estilo caótico e impreciso que no respeta al interlocutor. }\end{array}$ \\
\hline $\begin{array}{l}\text { 17. Símbolo del } \\
\text { autocontrol de la conducta }\end{array}$ & $\begin{array}{l}\text { Garantizar que el estilo interpersonal } \\
\text { transmitido se mantiene intacto. }\end{array}$ & $\begin{array}{l}\text { Que los docentes mantengan un diario semanal de reflexión } \\
\text { sobre su estilo de enseñanza y experiencias (cambio de } \\
\text { actitudes en los participantes, tasa de asistencia, etc.). } \\
\text { También recibir retroalimentación de los participantes y otros } \\
\text { expertos. }\end{array}$ \\
\hline 18. La práctica inmediata & $\begin{array}{l}\text { Se les pedirá a los educadores que apliquen las } \\
\text { estrategias de apoyo a la autonomía durante los } \\
\text { talleres y en sus clases. }\end{array}$ & $\begin{array}{l}\text { Transmisión de dicha información } \\
\text { a través de los talleres, estrategias, y ejemplos de } \\
\text { buenas prácticas que se proporciona en los planes de acción, } \\
\text { grupo de Facebook, y vídeos ilustrativos. } \\
\text { Debate grupal. }\end{array}$ \\
\hline
\end{tabular}

